OPEN ACCESS

Edited by:

M. Eric Gershwin,

University of California, Davis,

United States

Reviewed by:

Deepika Sharma

University of Chicago, United States

Pietro Invernizzi,

University of Milano Bicocca, Italy

*Correspondence:

Wei Zhang

zhangwei@/onghua.net

Specialty section:

This article was submitted to Autoimmune and Autoinflammatory

Disorders,

a section of the journal

Frontiers in Immunology

Received: 31 March 2019 Accepted: 15 November 2019 Published: 05 December 2019

Citation:

Cao H, Zhu B, Qu Y and Zhang W (2019) Abnormal Expression of ERa in

Cholangiocytes of Patients With

Primary Biliary Cholangitis Mediated Intrahepatic Bile Duct Inflammation.

Front. Immunol. 10:2815.

doi: 10.3389/fimmu.2019.02815

\section{Abnormal Expression of ER $\alpha$ in Cholangiocytes of Patients With Primary Biliary Cholangitis Mediated Intrahepatic Bile Duct Inflammation}

\author{
Hui Cao, Bukun Zhu, Yao Qu and Wei Zhang* \\ Department of Liver Diseases, Longhua Hospital, Shanghai University of Traditional Chinese Medicine, Shanghai, China
}

$\mathrm{ER} \alpha$, one of the classical receptors of estrogen, has been found to be abnormally up-regulated in patients with primary biliary cholangitis (PBC), which is an important factor leading to ductopenia. ER $\alpha$-mediated signaling pathways are involved in proliferation of human intrahepatic biliary epithelial cells (HiBECs) and portal inflammation. Our previous studies have shown that the expression levels of ER $\alpha$ in the liver tissues of PBC patients are positively correlated with the levels of serum pro-inflammatory cytokines. The present study was designed to assess the relationship between abnormal ER $\alpha$ expression in small bile ducts and the progression of PBC. We examined the levels of multiple cytokines and analyzed their relationship with clinical parameters of livers functions in a cohort of 43 PBC patients and 45 healthy controls $(\mathrm{HC})$. The levels of $\mathrm{ER} \alpha$ expression and the relation with the levels of cytokines were further assessed. The localization of cytokines and $E R \alpha$-mediated signaling pathways in liver were examined using immunohistochemistry. The possible underlying mechanisms of these alterations in PBC were explored in vitro. Our results demonstrated that the levels of IL-6, IL-8, and TNF- $\alpha$ were increased in PBC patients, and positively correlated with the serum AKP levels and ER $\alpha$ expression levels. Moreover, the expression of these cytokines were up-regulated in HiBECs that were stimulated with $17 \beta$-estradiol and PPT (an ER $\alpha$ agonist) and they also were positive in intrahepatic bile duct of PBC patients. The ER $\alpha$-mediated expression of pro-inflammatory cytokines was induced by JNK, P38, and STAT3 phosphorylation in HiBECs. In addition, the CD54 expression was increased in HiBECs after ER $\alpha$ activation, which induced peripheral blood monouclear cells (PBMCs) recruitment. In conclusion, the present study highlighted a key role of abnormal ER $\alpha$ expression in inducing an inflammatory phenotype of HiBECs, which was critical in the development of inflammation and damage in small bile duct.

Keywords: ER $\alpha$, pro-inflammatory cytokines, MAPKs, inflammatory cellular phenotype, PBC

\section{INTRODUCTION}

Primary biliary cholangitis (PBC) is an occult and chronic progressive autoimmune liver disease, and, if untreated, will culminate into end-stage biliary cirrhosis, leading to liver failure (1). Women are more susceptible to suffering this disease than men, although some recent data suggest an increasing male prevalence (2). According to epidemiologic studies, 1 in 1,000 women over the 
age of 40 live with PBC, and the estimated incidence is between 1 and 2 per 100,000 population per year in European populations (3); commonly cited ranges for incidence and prevalence are $0.3-$ 5.8 and $1.9-40.2$ per 100,000 , respectively (4). Nevertheless, the female predominance of $\mathrm{PBC}$ continues to be unexplained. The clinical features of $\mathrm{PBC}$ are persistent intrahepatic cholestasis and serologic reactivity to anti-mitochondrial antibodies (AMA) or specific antinuclear antibody (ANA) reactivity, with the pathological features being chronic non-suppurative, granulomatous, lymphocytic small bile duct cholangitis (5). The onset of the cholangitis is related to the multiple immune cells infiltration in the surrounding of the small bile duct. Previously, Tsuneyama et al. have reviewed the types of immune cells which infiltrate into the peripheral of small bile ducts in PBC patients; they have found that T cells comprise 55\% of the cellular infiltrate, macrophages and B cells/plasma cells account for $\sim 30$ and $10 \%$ in early stage, respectively, showing chronic non-suppurative destructive cholangitis (CNSDC), and these activated immune cells play important roles in initiating the breakdown of tolerance (6). Therefore, some scholars believe that the pathological starting point of PBC is autoimmune-mediated injury of small bile duct, and the immunological interaction between human intrahepatic biliary epithelial cells (HiBECs) and surrounding inflammatory cells is a pivotal mechanism to trigger small bile duct lesions (7). Interestingly, HiBECs, which are the main damaged cells in the early stage of PBC, may not be simply considered as an "innocent victim" of immune attack (8). Cholangiocytes in small bile duct of $\mathrm{PBC}$ patients are expressing various cytokines and chemokines in order to generate and sustain the specific surrounding inflammatory conditions, which will induce HiBECs apoptosis and exacerbate bile duct injury (6). Making the matters worse, the damaged HiBECs with aberrant expression of human leukocyte antigen (HLA) class II and other co-stimulatory molecules have an antigen-presenting ability (9). Hence, immunogenicity of HiBECs will be amplified. In addition, HiBECs in damaged biliary duct will have up-regulated expression of phagocytosis related receptor phosphatidylserine receptor (PSR), which is involved in phagocytosis of adjacent injured and apoptotic peers due to immunological interaction (10). And, normal HiBECs will express pyruvate dehydrogenase complex E2 (PDC-E2) after phagocytosed the adjacent injured and apoptotic peers (11). As a result, the immune tolerance of HiBECs will be impaired. Therefore, various types of migratory inflammatory cells become effector cells that are more aggressive to HiBECs $(11,12)$. However, effector cells also generate additional cytokines and chemokines to produce an inflammatory status and progressive fibrosis (12). Unfortunately, there is no clear mechanism to explain the causes of the onset abnormal activation of HiBECs.

Based on the clinical features of PBC that is predominant among perimenopause women, a previous study has shown that the abnormal expression of estrogen receptor $\alpha(\mathrm{ER} \alpha)$ in HiBECs of PBC patients is an important reason leading ductopenia (13). $\mathrm{ER} \alpha$ is one of the classical receptors of estrogen, and is often expressed at high levels in uterus, ovary, pituitary gland, vas deferens, and adipose tissues (14). Apparently, liver is also the target organ of estrogen, and the intrahepatic bile duct has up-regulated expression of $\mathrm{ER} \alpha$ under certain conditions (partial hepatectomy and bile duct ligation). However, ER $\alpha$-mediated signaling pathway can play multiple roles in bile duct, which stimulates HiBECs proliferation $(15,16)$ and is involved in portal inflammation that was induced by environmental xenoestrogens (17). Recently, some researchers have found that the soil in the high incidence area of PBC contains a large amount of xenobiotic that can activate $\operatorname{ER} \alpha$ (18). However, this study does not fully elucidate the relationship between ER $\alpha$ activation and pathogenesis of PBC.

In a preliminary study on the relationship of expression levels of $E R \alpha$ and serum cytokines of PBC patients, we found the expression levels of $\mathrm{ER} \alpha$ in liver of PBC patients were positively correlated with the serum levels of pro-inflammatory cytokines, such as IL-6, IL-8, and TNF- $\alpha$. In addition, it was further confirmed that $\mathrm{ER} \alpha$ was mainly expressed in the intrahepatic bile duct of the PBC patients. Therefore, we hypothesized that HiBECs would transform into an "inflammatory cellular phenotype" (higher expression pro-inflammatory cytokines and adhesion molecule) following $\mathrm{ER} \alpha$ activation resulting in multiple immune cells being recruited, and immune homeostasis of small bile duct being disturbed. The immunologic injury of HiBECs would evoke the onset of PBC. The present study was designed to test the above hypothesis in vitro and in vivo.

\section{MATERIALS AND METHODS}

\section{Patient Characteristics and Liver Tissue Samples}

Blood samples were collected from 43 PBC patients, before any ursodeoxycholic acid (UCDA), corticosteroids and sex hormone therapy at the Longhua hospital of Shanghai University of Traditional Chinese Medicine. Blood samples were also collected from 45 volunteers as healthy controls, who had normal ranges of routine physical examination (fasting blood glucose, liver and kidney function tests, blood lipids, urine, and stools) and without any acute or chronic liver diseases during routine checkup at the same hospital. The $10-\mathrm{mL}$ peripheral blood sample was collected from all the members and the concentrations of cytokines were measured. The liver biopsies were obtained from 8 post-menopausal women who needed to confirm this diagnosis by liver pathology. The pathological results confirmed the diagnoses of PBC in the 8 patients: 4 at stage II, 3 at stage III, and 1 at stage IV. As controls, 5 liver biopsies all showed normal histology. All PBC patients were negative for hepatitis $\mathrm{B}$ and $\mathrm{C}$ markers.

\section{Cell Culture and Stimulation}

HiBECs were purchased from tongpai biotechnology co., Ltd, and the cell line was confirmed by the expression of the biliary-type cytokeratins CK19 (using immune fluorescence) (Supplementary Figure 1A) and CK7 (using immunoblotting) (Supplementary Figure 1D), and the morphology of HiBECs was observed by optical microscope (Supplementary Figures 1B,C). HiBECs were suspended in RPMI 1640 medium (Invitrogen, California, USA) with 10\% fetal bovine serum supplemented with $10 \mathrm{ng} / \mathrm{mL}$ of epidermal growth 
factor (Sigma-Aldrich, Munich, Germany), $5 \mathrm{mg} / \mathrm{mL}$ insulin (Sigma-Aldrich, Munich, Germany), 100 units/ml penicillin, and $100 \mathrm{mg} / \mathrm{ml}$ streptomycin (Invitrogen, California, USA). When cells reached $60-70 \%$ of confluence, $17 \beta$-estradiol (SigmaAldrich, Munich, Germany), ER $\alpha$ agonist 4,4,4-(4-propyl-[1H] pyrazole-1,3,5-triyl)-tris-phenol (PPT) (Sigma-Alrich, Munich, Germany), ER $\beta$ agonist 2,3-bis (4-hydroxyphenyl)-propionitrile (DPN) (Sigma-Aldrich, Munich, Germany) and ER $\alpha$ antagonist fulvestrant (ICI182, 780) (Sigma-Aldrich, Munich, Germany) at various concentrations were added into the medium. The cells were cultured for $48 \mathrm{~h}$ and then harvested for further PCR and immunoblotting analyses.

\section{Real-Time PCR Analysis}

Real-time PCR analysis was performed using the SYBR-Green mix (Applied Biosystems, Foster City, CA, USA) in an ABI PRISM 7500HT sequence detector. Primers used for real-time RTPCR are shown in Supplementary Table 2. Briefly, total RNA was isolated and $1 \mathrm{mg}$ of RNA was reverse transcribed using RNA reverse transcription Kit (Takara, Kusatsu, Japan). The resultant cDNA was appropriately diluted and amplified in the SYBRGreen mix 10-ml system. The mRNA expression levels of IL-6, IL- 8 , TNF- $\alpha$, and other cytokines were normalized to the level of $\beta$-actin mRNA.

\section{Immunoblotting Analysis}

HiBECs were first lysed in RIPA buffer for $30 \mathrm{~min}$. The samples were separated by $12 \%$ SDS polyacrylamide gel electrophoresis (SDS-PAGE) at $80 \mathrm{~V}$ for $0.5 \mathrm{~h}$ and $100 \mathrm{~V}$ for $1 \mathrm{~h}$ before transfer onto polyvinylidene difluoride membranes (PVDF). After blocking, the blots were incubated overnight with $4^{\circ} \mathrm{C}$ with hybridized with primary Abs. ER $\alpha$ (1:200) (Novus Biologicals, Colorado, USA), ER $\beta$ (1:500) (R\&D Systems, Minnesota, USA), P-JNK (1:250) (CST, Boston, USA), P38 (1:500) (CST, Boston, USA), P-STAT3 (1:200) (CST, Boston, USA), and GAPDH (1:1000) (CST, Boston, USA). The blots were then washed with PBST and then incubated for $1 \mathrm{~h}$ with secondary antibodies conjugated to horseradish peroxidase (1:5000) (CST, Boston, USA). The membranes were scanned with a LAS-4000 luminescent image analyzer (Bio-Rad, California, USA). Digital images of resultant chemiluminescent signals were analyzed using Image Lab software (Bio-Rad, California, USA).

\section{PBMC Preparation and Adhesion Assay}

Freshly isolated peripheral blood mononuclear cells (PBMCs) were extracted from $20 \mathrm{~mL}$ of fresh heparinized blood samples of PBC patients and healthy controls, using human lymphocyte separation solution (Sigma-Aldrich, Munich, Germany). The PBMCs were cultured in RPMI 1640 medium supplemented with $10 \%$ fetal bovine serum, $100 \mathrm{mg} / \mathrm{mL}$ of penicillin, and $100 \mathrm{mg} / \mathrm{mL}$ of streptomycin. To obtain mitogen- activated lymphocytes, the PBMCs were stimulated with $10 \mathrm{mg} / \mathrm{mL}$ of phytohemag glutinin (Sigma-Aldrich, Munich, Germany) for $72 \mathrm{~h}$ at $37^{\circ} \mathrm{C}$. The cell adhesion assay was modified as described previously (19). Briefly, the PBMCs were labeled with BCECFAM $(5 \mu \mathrm{g} / \mathrm{mL})$ (Beyotime Biotechnology, Shanghai, China) for
$1 \mathrm{~h}$ at $37^{\circ} \mathrm{C}$, washed three times with sterile PBS, and resuspended in serum free RPMI 1640 medium. The HiBECs were incubated with reagents on a 24-well culture plate, and then cocultured with BCECF-AM-labeled PBMCs for $1 \mathrm{~h}$ at $37^{\circ} \mathrm{C}$. Nonadhering PBMCs were removed by pipette, and the wells were washed with sterile PBS. The PBMCs binding to HiBECs were measured by fluorescence microscope. The fluorescence intensity was analyzed by ImageJ (National Institutes of Health, Bethesda, MD, USA).

\section{Flow Cytometric Analysis}

Flow cytometry was performed as described previously (20). Briefly, HiBECs were incubated with reagents on a 6-well culture plate for $48 \mathrm{~h}$, and then rapidly digested and centrifuged, washed, re-suspended and stained according to standard protocols using the following mAbs:CD54 (BD Biosciences, New Jersey, USA), CD106 (BD Biosciences, New Jersey, USA), and CD58 (BD Biosciences, New Jersey, USA). These markers were used to observe the changes of adhesion molecules in HiBECs after incubated with reagents. Data acquisition was performed using a BD Biosciences LSR Fortessa cytometer (BD Biosciences, New Jersey, USA), and results were analyzed using FlowJo analysis software (BD Biosciences, New Jersey, USA).

\section{Immunofluorescence Analysis}

The protocol was performed as our laboratory standard. Briefly, formalin-fixed paraffin-embedded tissue sections were deparaffinized and rehydrated. Blocking of endogenous avidin/biotin, and antigen retrieval was performed by boiling the sections in $0.01 \mathrm{M}$ sodium citrate for $24 \mathrm{~min}$. The sections were then incubated in $0.1 \%$ triton for $10 \mathrm{~min}$ and blocked with 5\% BSA for $60 \mathrm{~min}$, and then incubated with primary antibodies: rabbit anti-human CD54 antibody (CST, Boston, USA), and mouse anti-human ER $\alpha$ antibody (Novus Biologicals, Colorado, USA), at $4^{\circ} \mathrm{C}$ overnight. Following washing, the tissues sections were incubated with alexa fluor 594-affinipure donkey anti-mouse IgG (Yeasen, Shanghai, China) and alexa fluor 488-affinipure goat anti- rabbit IgG (Yeasen, Shanghai, China) for $60 \mathrm{~min}$ at $37^{\circ} \mathrm{C}$. Finally, the cell nuclei were stained by DAPI. The results were examined under a fluorescence microscope.

\section{Immunohistochemistry}

Immunohistochemistry analysis was completed as previously reported (21). Briefly, formalin-fixed paraffin-embedded tissue sections were deparaffinized and rehydrated. Blocking of endogenous avidin/biotin, and antigen retrieval was performed by boiling in $0.01 \mathrm{M}$ sodium citrate for $24 \mathrm{~min}$. The sections were then blocked with 5\% BSA for $30 \mathrm{~min}$, and then incubated with primary antibodies: rabbit anti-human PJNK antibody (CST, Boston, USA), rabbit anti-human PSTAT3 antibody (CST, Boston, USA), mouse anti-human ER $\alpha$ antibody (Novus Biologicals, Colorado, USA), mouse antihuman ER $\beta$ antibody (R\&D Systems, Minnesota, USA), rabbit anti-human IL-6 antibody (CST, Boston, USA), mouse antihuman IL-8 antibody (Santa Cruz Biotechnology, Dallas, USA), rabbit anti-human TNF- $\alpha$ antibody (CST, Boston, 
USA), rabbit and anti-human CK-19 antibody (HUA BIO, Hangzhou, China) at $4^{\circ} \mathrm{C}$ overnight. Following washing, tissues sections were incubated with horseradish peroxidase conjugated anti-mouse or rabbit anti-bodies (CST, Boston, USA) for $30 \mathrm{~min}$ at $37^{\circ} \mathrm{C}$. Specific staining was detected by 3, 3diaminobenzidine and examined by light microscopy. Tissue sections were evaluated using Image pro plus (Media cybernetics, Maryland, USA).

\section{Statistical Analysis}

The statistical significance of the differences in the levels of cytokines between PBC patients and healthy controls were analyzed using Non-parametric test. Linear relation were performed using Spearman's rank correlation to assess the relationship between $\mathrm{ER} \alpha$ expression levels, cytokine levels and liver function. Independent samples were analyzed using Student's $t$-test or one-way analysis of variance unless indicated in the figure legends. Statistical analyses were performed on raw data using Graph Pad software and SPSS 21. All of the Pvalues were shown as two-sided; and $P<0.05$ was considered statistically significant.

\section{RESULTS}

\section{The Serum Levels of IL-6, IL-8, and TNF- $\alpha$ in PBC Patients Are Higher Than That in \\ Control Subjects}

We recruited $43 \mathrm{PBC}$ patients and 45 healthy controls (HC) in the present study. The mean ages of $\mathrm{PBC}$ patients and $\mathrm{HC}$ were almost the same, and the characteristics of $\mathrm{PBC}$ patients
A

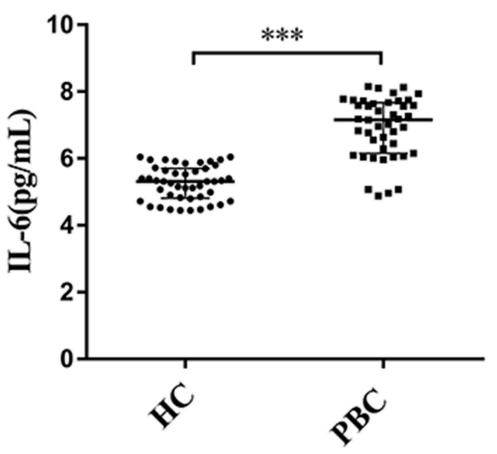

D

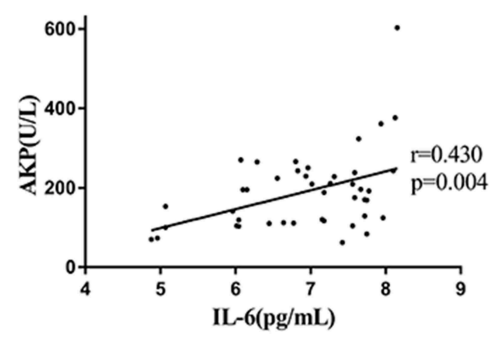

G

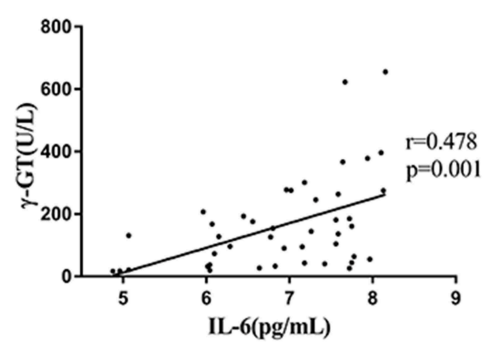

B

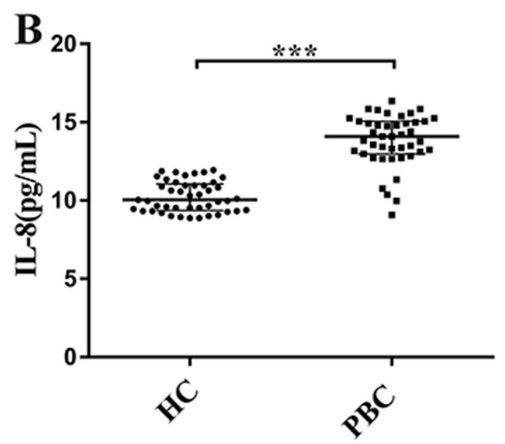

E

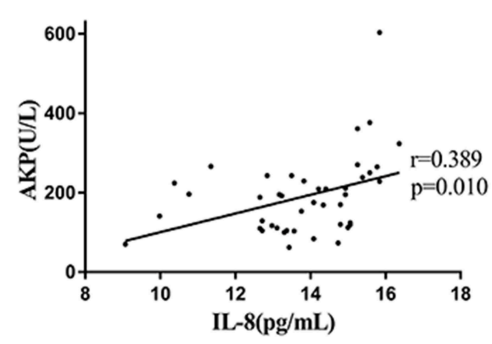

H

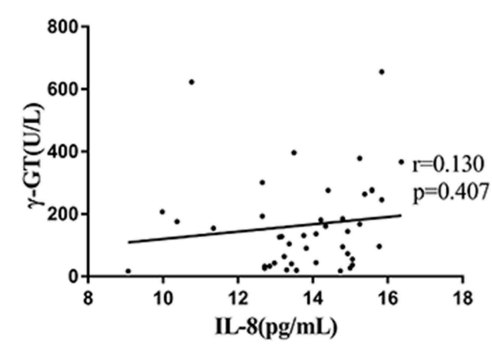

C

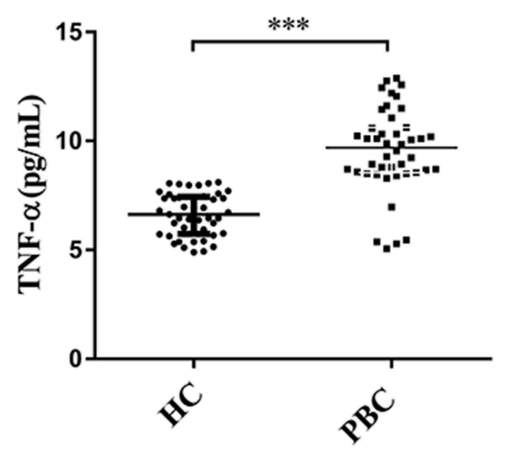

F

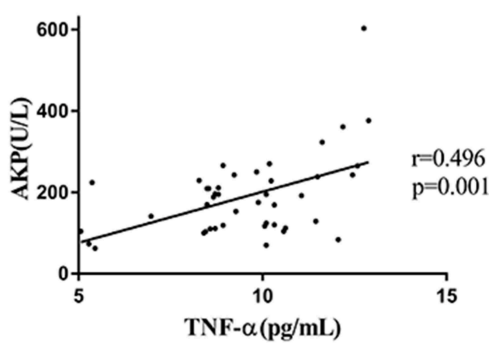

I

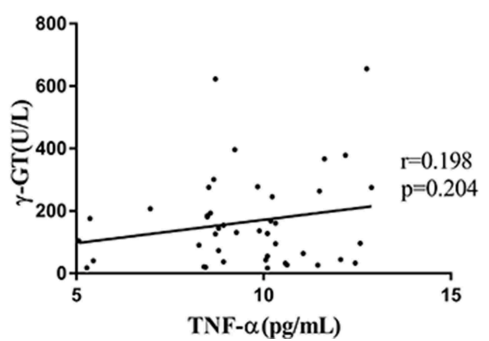

FIGURE 1 | Serum levels of cytokines and correlation with AKP and $\gamma$-GT. (A-C) Serum levels of IL-6 (A), IL-8 (B), and TNF- $\alpha$ (C) in PBC patients $(n=43)$ and HC $(n$ $=45),{ }^{* \star} P<0.001$, compared with HC by a Mann-Whitney test. Data are represented as median with interquartile range. (D-F) Serum IL-6 (D), IL-8 (E), and TNF- $\alpha$ (F) concentration with the levels of AKP in PBC patients $(n=43) . r=0.430, p=0.004$ (IL-6); $r=0.389, p=0.010$ (IL-8) and $r=0.496, p=0.001$ (TNF- $\alpha$ ), respectively. (G-I) Serum IL-6 (G), IL-8 (H), and TNF- $\alpha$ (I) concentration with the levels of $\gamma$-GT in PBC patients $(n=43) . r=0.478, p=0.001$ (IL-6); $r=0.130, p=$ 0.407 (IL-8) and $r=0.198, p=0.204$ (TNF- $\alpha$ ), respectively. The $p$-values were determined by Spearman's rank correlation, $P<0.05$ was considered significant. PBC, primary biliary cholangitis; HC: healthy control; IL-6, interleukin-6; IL-8, interleukin-8; TNF- $\alpha$; tumor necrosis factor-alpha; AKP, Alkaline phosphatase; $\gamma$-GT, g-glutamyl transpeptidase. 
and healthy controls are shown in Supplementary Table $\mathbf{1}$ ). The median values of AKP, $\gamma$-GT and TBiL in PBC patients were $195.29 \mathrm{U} / \mathrm{L}, 131.00 \mathrm{U} / \mathrm{L}$ and $13.20 \mu \mathrm{mol} / \mathrm{L}$, respectively. We next tested the serum multiple cytokines levels of PBC patients and HC (Supplementary Figure 2). We found that the levels of IL-6, IL-8, and TNF- $\alpha$ in the patients were higher than that in HC (Mann-Whitney test $Z=-6.997, P<0.001$; $Z=-7.180, P<0.001 ; Z=-6.599, P<0.001$, respectively) (Figures 1A-C). Moreover, as Li et al. (22) proposed, the serum abnormal cytokines levels may have a linear relationship with the parameters for liver functions (AKP, $\gamma$-GT, and TBiL) in PBC patients. As expected, the results from the present study showed that there were a positive correlations between the levels of AKP and IL-6 $(r=0.430, p=0.004)$, IL-8 $(r=0.389, p=0.010)$ and TNF- $\alpha(r=0.496, p=0.001)$ (Figures 1D-F). However, the levels of $\gamma$-GT were not positive correlated with IL-8 $(r=0.130$, $p=0.407)$, and TNF- $\alpha(r=0.198, p=0.204)$, except for IL-6 ( $r$ $=0.478, p=0.001)$ (Figures 1G-I). In addition, we did not find the levels of TBiL has linear relationships with the serum levels of IL-6, IL-8, and TNF- $\alpha$ Supplementary Figures $2 \mathrm{M}-\mathbf{O}$ ). And there were no correlations with other cytokines (Supplementary Figures 2A-S).

\section{The ER $\alpha$ Expression Levels in Small Bile Ducts Are Positively Correlated With the Serum Cytokines Levels in PBC Patients}

In our previous study, we found that the ER $\alpha$ expression levels in the liver were positively correlated with the concentrations of various pro-inflammatory cytokines in $\mathrm{PBC}$ patients. However, the location of ER $\alpha$ expression was not detected precisely. Hence, we selected some liver biopsies from 8 PBC patients, the location and levels of $\mathrm{ER} \alpha$ expression in the small bile ducts were tested by immunohistochemistry analysis. Then, we assessed the linear relationship between ER $\alpha$ expression levels and serum cytokines levels. In addition, to find out the small bile ducts in portal area, we selected biliary-type cytokeratin CK19 as a biomarker and determined the ER $\alpha$ expression level in the CK19positive areas. The results of immunohistochemistry showed that positive expression of $\mathrm{ER} \alpha$ (both cytoplasm and nucleus) was mainly located in intrahepatic bile ducts, which was consistent with CK19-positive area (lower right panel) (Figures 2E,F). Similar to previous research, normal small bile ducts in $\mathrm{HC}$ did not express ER (upper right panel) (Figures 2B,C). Further analysis indicated that $\mathrm{ER} \alpha$ expression levels in small bile duct of $\mathrm{PBC}$ patients were significantly higher than that in HC (Figure 2G).

Next, the linear relationship between ER $\alpha$ expression levels and serum levels of IL-6, IL-8 and TNF- $\alpha$ was analyzed using spearman's rank correlation. Indeed, there were a positive correlations between $\mathrm{ER} \alpha$ and the cytokines ( $r$ $=0.786, p=0.021 ; r=0.723, p=0.043$ and $r=$ $0.758, p=0.029$ for IL-6, IL-8, and TNF- $\alpha$, respectively) (Figures 2H-J). Although ER $\beta$ expression in small bile ducts of $\mathrm{PBC}$ patients was detected by immunohistochemistry, the ER $\beta$ expression levels were not related with cytokines levels (Supplementary Figure 3).

\section{$17 \beta$-Estradiol Induces the Expressions of IL-6, IL-8, and TNF- $\alpha$ in HiBECs}

As shown in Figure 2, the expression levels of ER $\alpha$ were involved in pro-inflammatory cytokines expression in PBC patients. Hence, we wanted to confirm it in vitro. $17 \beta$-estradiol was a classic steroid hormone was selected and its concentrations used in vitro were roughly equivalent to those in postmenopausal female $(0.1 \mathrm{nM})$, normal premenopausal female $(10 \mathrm{nM})$, and pregnant female $(100 \mathrm{nM})(21)$, respectively. Under normal conditions, HiBECs did not or slightly expressed ER $\alpha$ protein. In the present study, we observed the ER $\alpha$ and cytokines (IL-6, IL- 8 , and TNF- $\alpha$ ) expressions in HiBECs that were stimulated by three concentrations of $17 \beta$-estradiol at four time-points $(0,12,24$, and $48 \mathrm{~h})$. The RT-PCR results showed that the expression levels of IL-6, IL-8, and TNF- $\alpha$ mRNAs were not changed in HiBECs that were stimulated with $17 \beta$-estradiol for 12 and $24 \mathrm{~h}$ (Figures 3A-C). However, the expression levels of IL-6, IL-8, and TNF- $\alpha$ mRNA in HiBECs that was treated with $10 \mathrm{nM} 17 \beta$-estradiol for $48 \mathrm{~h}$ were higher than that in the controls (Figures 3D-F). It is worth noting that higher doses of $17 \beta$-estradiol might have a negative impact on cytokines expression [the immunosuppressive action of high concentration of estrogen (12)]. Subsequently, the levels of cytokines (IL-6, IL-8, and TNF- $\alpha$ ) protein in the cell culture supernatant were analyzed by Elisa kit. The results were consistent with RT-PCR, and $10 \mathrm{nM} 17 \beta$-estradiol might be an ideal reagent to induce expression of IL-6, IL-8, and TNF- $\alpha$ in HiBECs (Figures 3G-I). Finally, we detected the expression of two kinds of estrogen receptors (ER $\alpha$ and ER $\beta)$. HiBECs were stimulated with $17 \beta$-estradiol $(10 \mathrm{nM})$ for four time periods $(0,12,24$, and $48 \mathrm{~h})$, and $\mathrm{ER} \alpha$ and ER $\beta$ proteins were analyzed by immunoblotting. We found the levels of ER $\alpha$ expression were gradually increased along with the increase in exposure time, but did not find the statistic difference among control groups and 17/-estradiol groups at 0,12 , and $24 \mathrm{~h}$ (Figures $3 \mathbf{J}, \mathbf{K}$ ). However, the levels of ER $\alpha$ expression in HiBECs at $48 \mathrm{~h}$ were significantly higher than that in control groups (Figures 3J,K). And, it was not observed any significant difference in ER $\beta$ expression between control groups and $17 \beta$-estradiol groups (Figures 3J,L). Taken together, these data provided an evidence that $17 \beta$ estradiol could induce cytokines expression in HiBECs via activated $\mathrm{ER} \alpha$.

\section{Fulvestrant Effectively Blocks $17 \beta$-Estradiol-Mediated Cytokines Expression in HiBECs}

In order to further verify that the $17 \beta$-estradiol-mediated proinflammatory cytokines expression in HiBECs was dependent of $\mathrm{ER} \alpha$ activation. we used the $\mathrm{ER} \alpha$ agonist 4,4,4-(4-propyl$[1 \mathrm{H}]$ pyrazole-1,3,5-triyl)-tris-phenol (PPT) and the ER $\beta$ agonist 2,3-bis (4-hy droxyphenyl)-propionitrile (DPN) that were added to HiBECs parallel with $17 \beta$-estradiol $(10 \mathrm{nM})$ or vehicle in the present experiments. And the fulvestrant (ICI182, 780, $\mathrm{ER} \alpha$ antagonist) was added to HiBECs $2 \mathrm{~h}$ before stimulation with $17 \beta$-estradiol. 

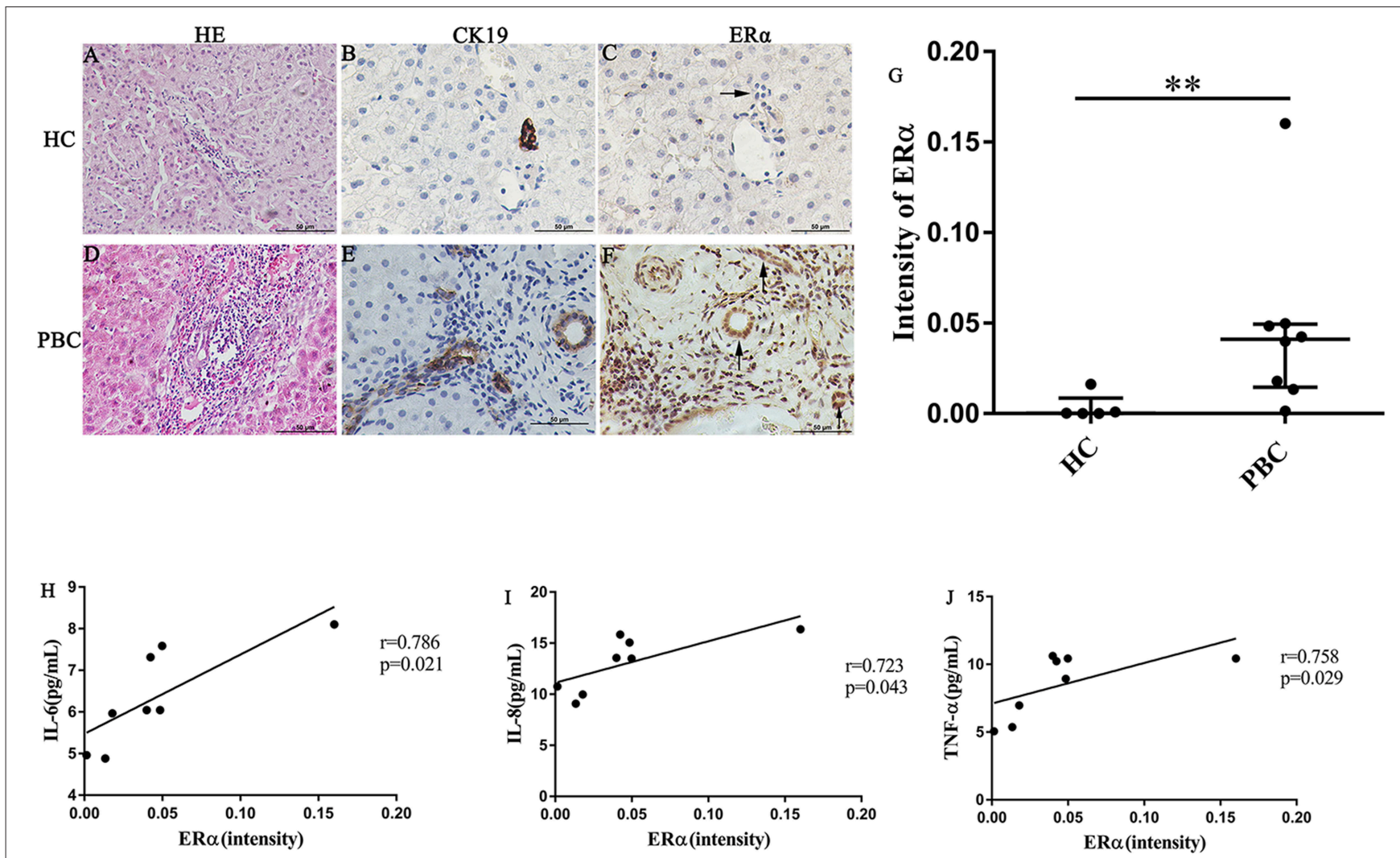

FIGURE 2 | ER $\alpha$ expression in liver biopsies of PBC patients, HC and correlation with cytokines. (A-J) A significant immunohistochemical ER $\alpha$ positive expression in cholangiocytes of PBC patients (F) ( $n=8$, both cytoplasm and nucleus) (lower right panel), but negatively in $\mathrm{HC}(n=5)$ (upper right panel) (original magnification, $\times 400)$. (G) ER $\alpha$ expression was higher in patients with PBC, ${ }^{* *} p<0.01$, compared with $\mathrm{HC}$ by a Mann-Whitney test. Data are represented as median with interquartile range. (H-J) Serum IL-6 (H), IL-8 (I), and TNF- $\alpha(\mathbf{J})$ level with the intensity of ER $\alpha$ in PBC patients. The $p$-values were determined by Spearman's rank correlation, $P<0.05$ was considered significant. PBC, primary biliary cholangitis; HC: healthy control; IL-6, interleukin-6; IL-8, interleukin-8; TNF- $\alpha$; tumor necrosis factor-alpha; $E R \alpha$, estrogen receptor alpha.

The results showed that PPT $(100 \mathrm{nM})$ could up-regulate the IL-6, IL-8, and TNF- $\alpha$ mRNA expression in HiBECs (Figures 4A-C), and it was similar to $17 \beta$-estradiol $(10 \mathrm{nM})$. However, we did not observed that the expression of IL6, IL-8, and TNF- $\alpha$ mRNA in HiBECs were up-regulated by stimulation of DPN (Figures 4A-C). As expected, the IL-6, IL8 , and TNF- $\alpha$ mRNA expressions in HiBECs were significantly down-regulated by pretreatment with fulvestrant $(8.24 \mu \mathrm{M})$ for $2 \mathrm{~h}$ (Figures 4A-C). Then, the cytokines proteins in the cell culture supernatant of all groups were analyzed by Elisa kits. The results were consistent with RT-PCR, and the protein levels of IL-6, IL-8, and TNF- $\alpha$ in HiBECs that were treated with $17 \beta$ estradiol $(10 \mathrm{nM})$ and PPT $(100 \mathrm{nM})$ were higher than that in controls (Figures $4 \mathrm{D}-\mathrm{F})$. Indeed, fulvestrant $(8.24 \mu \mathrm{M})$ blocked $17 \beta$-estradiol-mediated these cytokines expression in HiBECs (Figures 4D-F).

Finally, the ER $\alpha$ expression levels in HiBECs that were stimulated with PPT, DPN, 17 $\beta$-estradiol, and fulvestrant were tested by immunoblotting analyses. The results showed that the $\mathrm{ER} \alpha$ expression levels were up-regulated in HiBECs that were treated with $17 \beta$-estradiol and PPT (Figures 4G,H), and fulvestrant showed an inhibitory effect on ER $\alpha$ expression (Figures 4G,H). However, ER $\beta$ expression was not changed in all groups, except for the DPN groups (Figures 4G,I). Taken together, these data provided additional evidences for that $\mathrm{ER} \alpha$ activation was accounting for pro-inflammatory cytokines expression in HiBECs.

\section{The ER $\alpha$-Mediated IL-6, IL-8, and TNF- $\alpha$ Expressions in HiBECs Are via Activated MAPKs Pathway}

As previously reported, estrogen induces cholestasis and cholangiocyte proliferation via activating the MAPK pathways (ERK1/2, JNK, and P38) $(23,24)$. In addition, P38-MAPK is often over activated within inflamed tissues and accounts for the progression of biliary cirrhosis (25). Hence, we wanted to find out whether ER $\alpha$-induced pro-inflammatory cytokines expression in HiBECs via activated MAPKs signaling pathways. Firstly, JNK and P38 phosphorylation were tested after $\mathrm{ER} \alpha$ was activated. HiBECs were treated with $17 \beta$-estradiol $(10 \mathrm{nM})$, and those proteins phosphorylation were detected by immunoblotting 


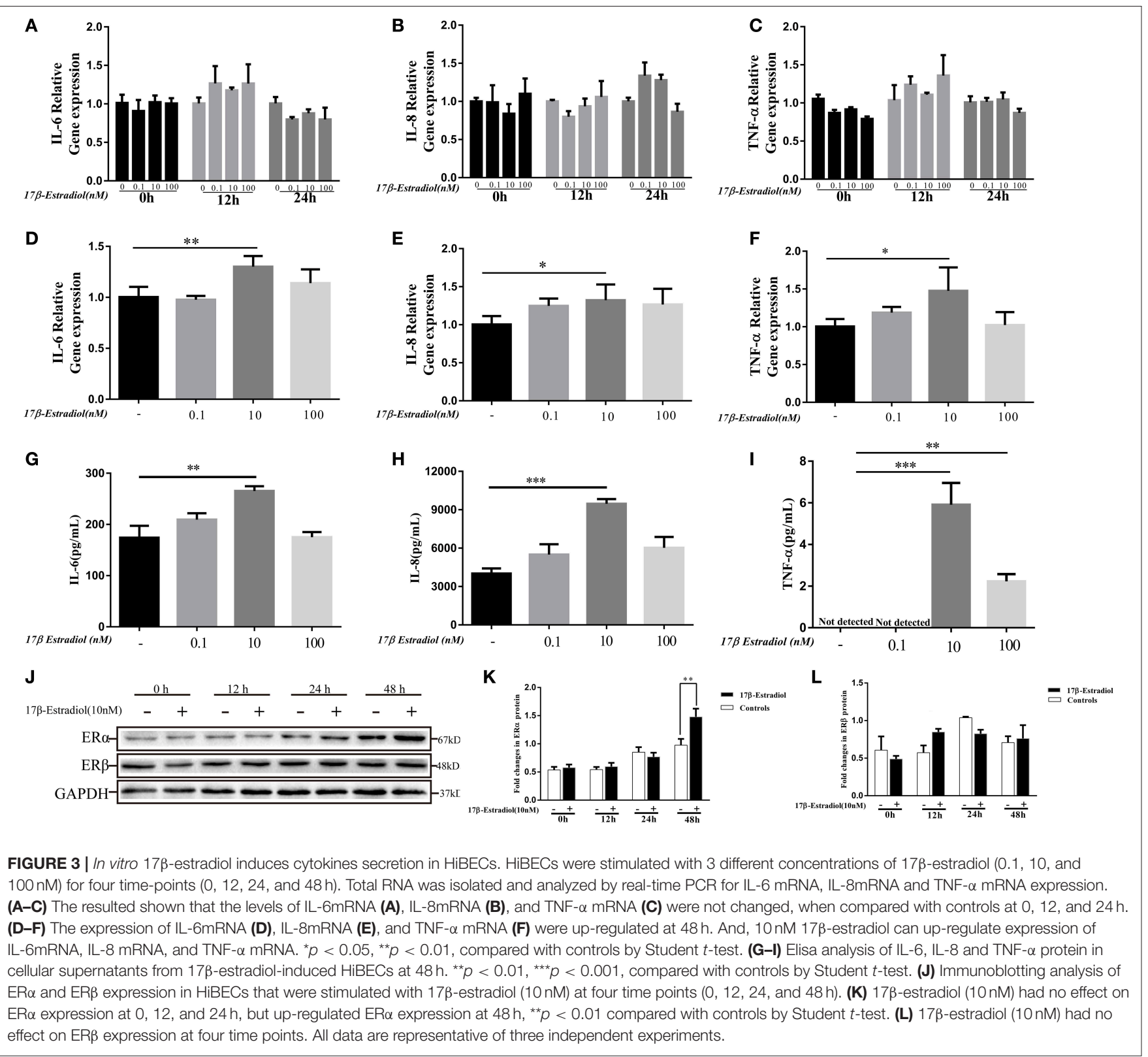

analysis. The results indicated that the levels of P-JNK and P-P38 were up-regulated in HiBECs (Figures 5A,C). At the same time, we detected whether the expression of tyrosinephosphorylated STAT3 (P-STAT3) that is a key protein involved in cytokines expression was also up-regulated in HiBECs. PSTAT3 can be translocated to the nucleus where they regulate transcription by binding to specific DNA sequences (26). In addition, it is reported that P38/STAT3 pathway is involved in inflammatory disorders (27). As expected, our results showed that the levels of P-STAT3 was up-regulated (Figures 5A,C). It was worth noting that the STAT3 activation was blocked by SB203580 (a P38 activation inhibitor), but not affected by SP600125 (JNK activation inhibitor) (Supplementary Figure 4).
Hence, we considered JNK and P38/STAT3 accounted for $17 \beta$ mediated cytokines expression in HiBECs.

Subsequently, we wanted to confirm that the phosphorylation of JNK, P38, and STAT3 were associated with ER $\alpha$ activation. Hence, as mentioned above, $17 \beta$-estradiol $(10 \mathrm{nM})$, and PPT $(100 \mathrm{nM})$ were added to HiBECs parallel with vehicle. And fulvestrant was added to HiBECs $2 \mathrm{~h}$ before stimulation with $17 \beta$-estradiol. Our results showed that PPT could induce JNK, P38, and STAT3 phosphorylation (Figures 5B,D-F) as well as $17 \beta$-estradiol (Figures 5C-F). Furthermore, fulvestrant showed an inhibitory effect on the phosphorylation of JNK, P38 and STAT3, which should be up-regulated by $17 \beta$-estradiol (Figures 5B,D-F). 


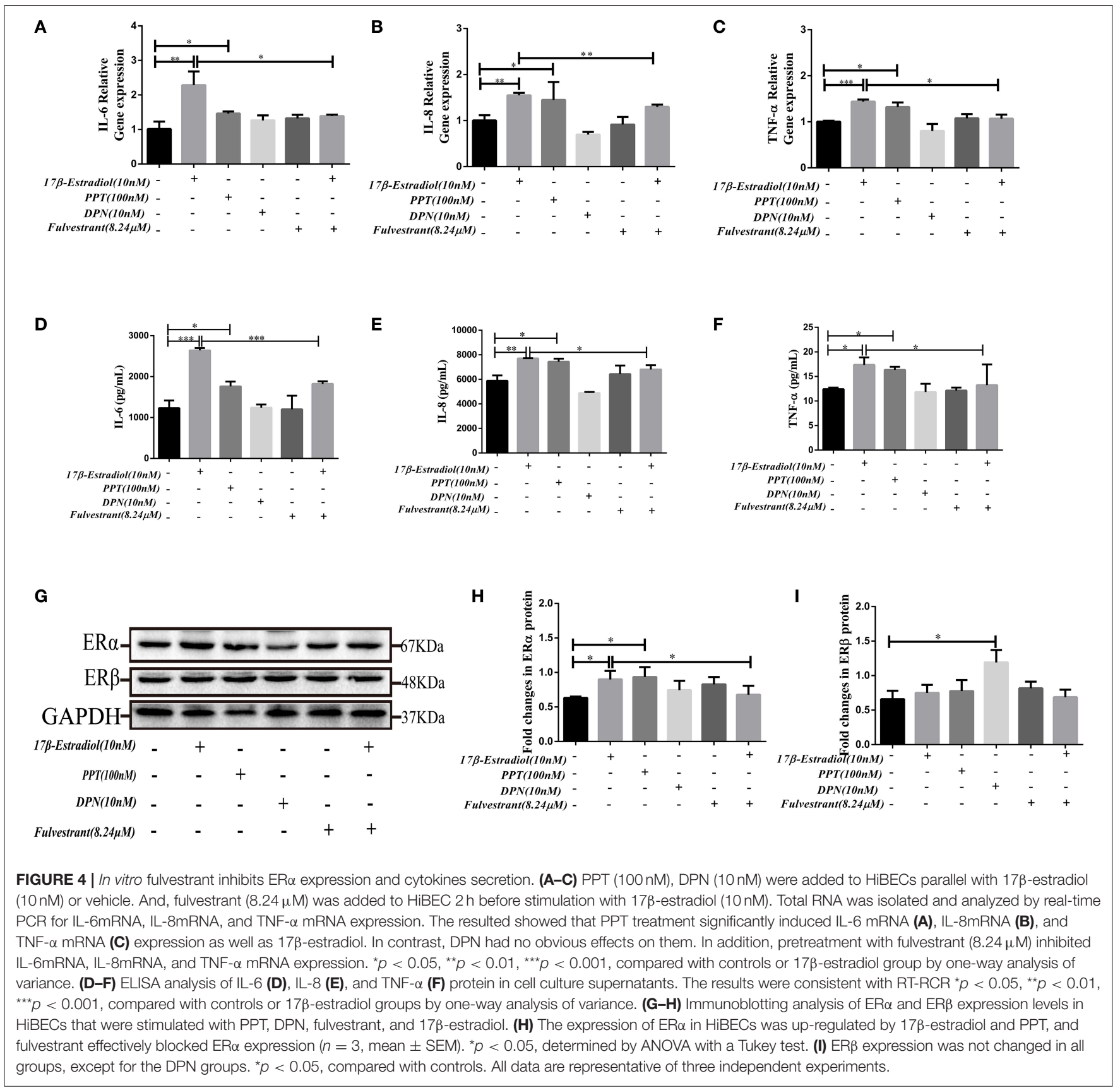

Finally, we wanted to determine the IL-6, IL-8, and TNF- $\alpha$ expression in HiBECs after JNK and P38 pathways were blocked by SP600125 and SB203580.2 $\mu \mathrm{M}$ SP600125, $2 \mu \mathrm{M}$ SB203580 and a combination of both were added to HiBECs $2 \mathrm{~h}$ before stimulation with $17 \beta$-estradiol and PPT. And, 17 $\beta$-estradiol, PPT were added to HiBECs parallel with vehicle. The cell culture supernatants of all groups were collected and analyzed by Elisa kits. We found that the levels of TNF- $\alpha$ were down-regulated in pretreatment of SP600125, SB203580 and a combination of both, when compared with 17ß-estradiol and PPT (Figures 5G,H).
Although the levels of IL-8 were not affected by pretreatment with SP600125, it was reduced by pretreatment with a combination of both (Figures 5G,H). However, at same time, we did not find significant statistical difference in IL-6 expression in HiBECs that were pretreated with SP600125 or SB203580, when compared with 17ß-estradiol and PPT (Figures 5G,H). However, it was down-regulated by pretreatment with SP600125 and SB203580 (Figures 5G,H). Taken together, our results showed that ER $\alpha$-mediated proinflammatory cytokines expression was via activated JNK and P38/STAT3 pathway. 
A

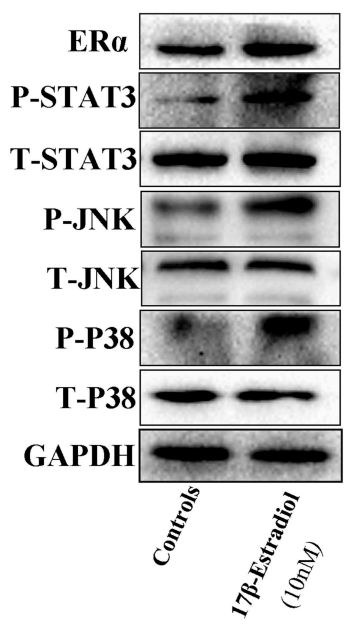

C

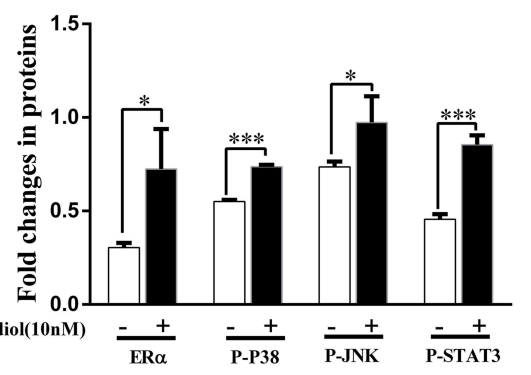

E

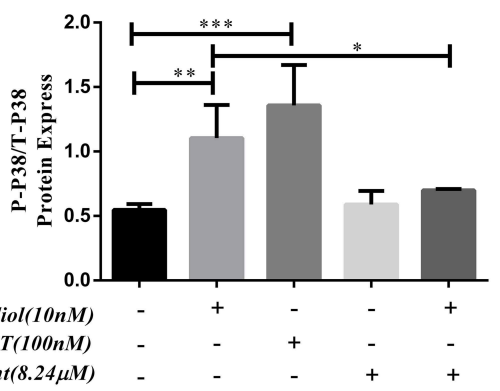

B

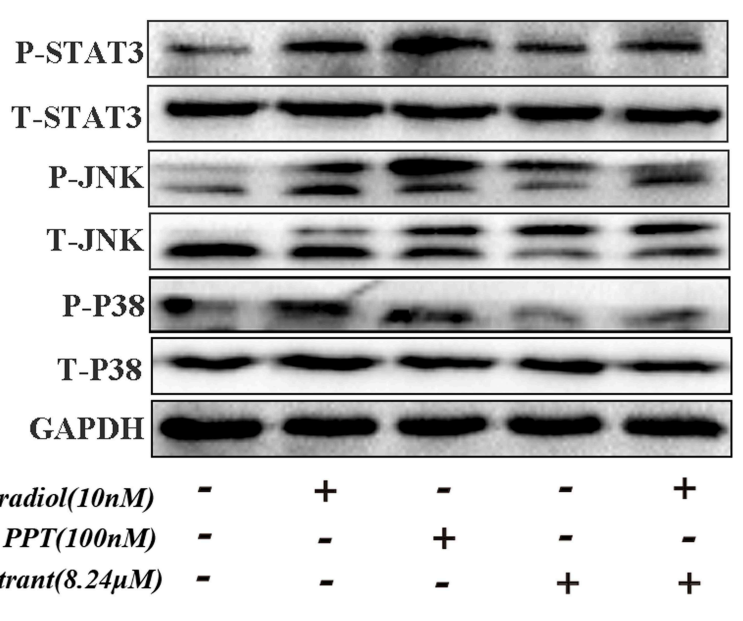

17 $\beta$-Estradiol

$\square$ Controls

D

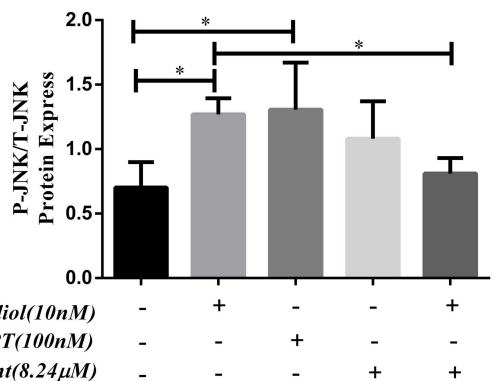

$\mathbf{F}$

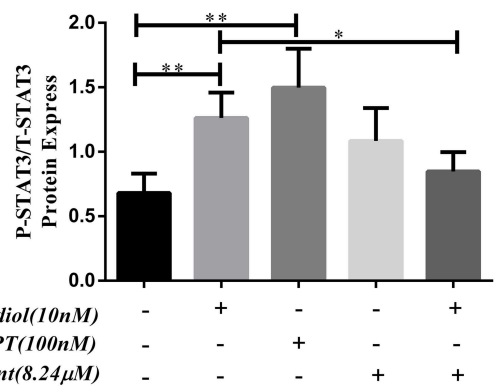

G

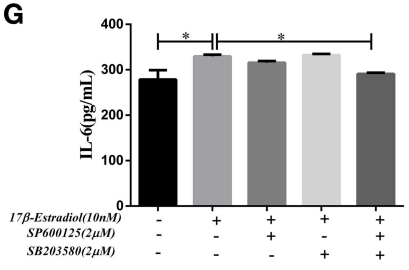

H

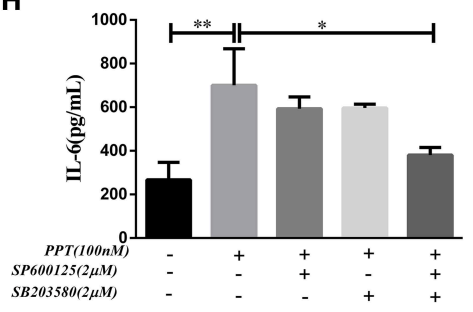

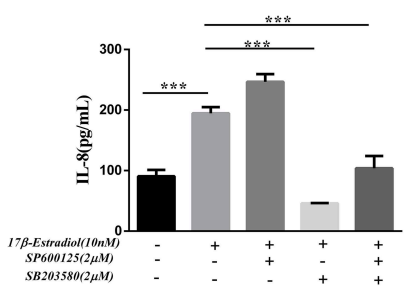

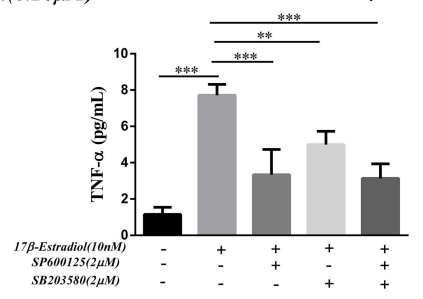

FIGURE 5 | ER $\alpha$-mediated JNK, P38 and STAT3 activation. (A) Immunoblotting analysis of JNK, P38, and STAT3 activation in HiBECs which were stimulated with $17 \beta$-estradiol (10 nM). (B) Immuno blotting analysis of JNK, p38, and STAT3 activation in HiBECs which were stimulated with PPT (100 nM), fulvestrant (8.24 $\mu$ M), and (Continued) 
FIGURE 5 | 17ß-estradiol (10 nM). (C) Significant increase of JNK, P38, and STAT3 phosphorylation following $17 \beta$-estradiol treatment $\left(n=3\right.$, mean \pm SEM). ${ }^{*} p<$ $0.05,{ }^{* \star *} p<0.001$, compared with controls by a Student $t$-test. (D-F) The phosphorylation of JNK (D), P38 (E), and STAT3 (F) were up-regulated in HiBECs which were stimulated with PPT and $17 \beta$-estradiol, but, it was reduced by fulvestrant $\left(n=3\right.$, mean \pm SEM). ${ }^{*} p<0.05,{ }^{* \star} p<0.01$, ${ }^{* \star *} p<0.001$, determined by ANOVA with a Tukey test. (G,H) SP600125 (2 $\mu \mathrm{M})$, SB203580 $(2 \mu \mathrm{M})$ and a combination of both were added to HiBECs $2 \mathrm{~h}$ before stimulation with $17 \beta$-estradiol (10nM) and PPT $(100 \mathrm{nM})$. At same time, $17 \beta$-estradiol and PPT were added to HiBECs parallel with vehicle. (G) Cell culture supernatants of all groups (17 $\beta$-estradiol (10 nM), SP600125 $(2 \mu \mathrm{M})$, SB203580 $(2 \mu \mathrm{M})$ and a combination of both) were collected and analyzed by Elisa for IL-6, IL-8, and TNF- $\alpha$ protein expression in HiBECs. ${ }^{*} P<$ $0.05,{ }^{* \star} p<0.01,{ }^{* \star *} p<0.001$, determined by ANOVA with a Tukey test. (H) Cell culture supernatants of all groups (PPT (100 nM), SP600125 (2 $\mu$ M), SB203580 $(2 \mu \mathrm{M})$ and a combination of both) were analyzed by Elisa for IL-6, IL-8, and TNF- $\alpha$ protein expression in HiBECs $\left(n=3\right.$, mean \pm SEM). ${ }^{*} p<0.05,{ }^{* *} p<0.01,{ }^{* \star *} p<$ 0.001 , determined by ANOVA with a Tukey test. All data are representative of three independent experiments.
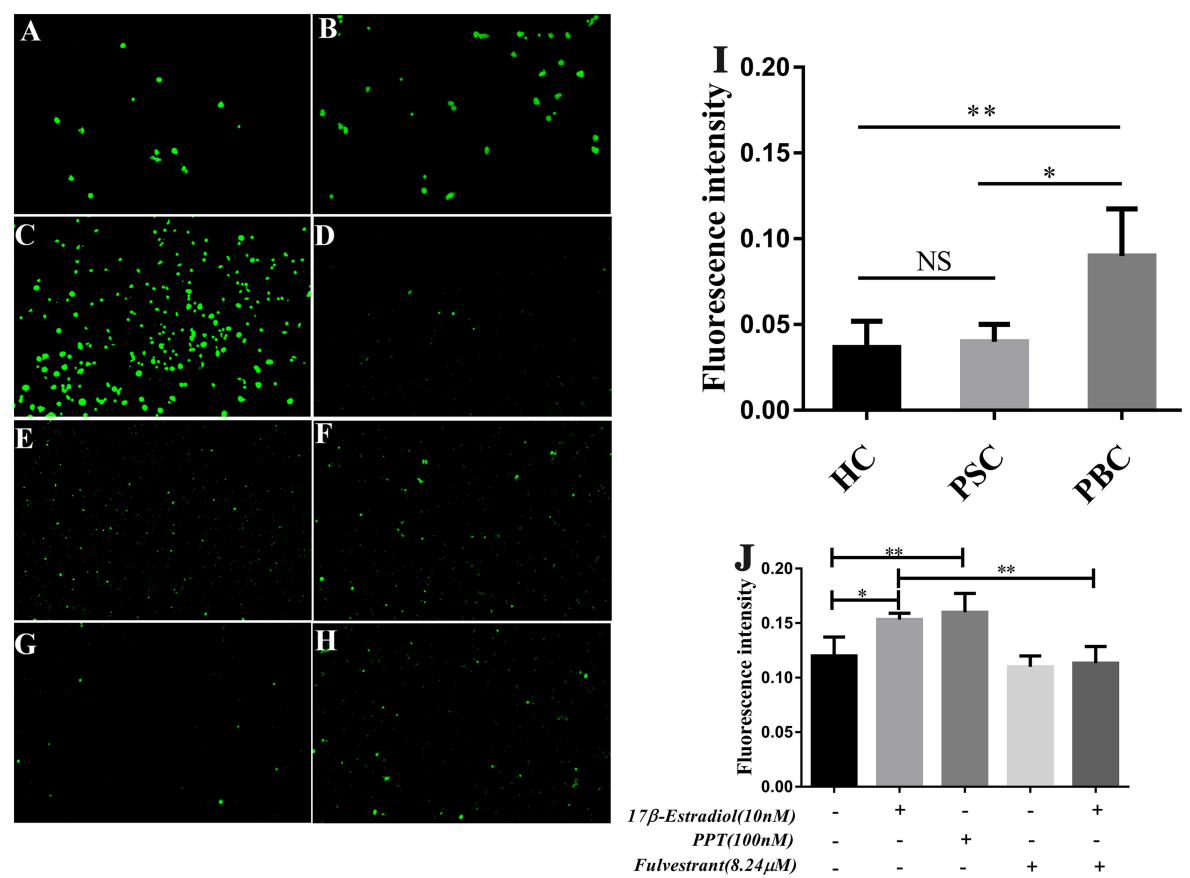

FIGURE 6 | PBMCs activation in PBC patients and prone to binding to HiBECs after ER $\beta$ expression was up-regulated. (A-C) PBMCs were extracted from $10 \mathrm{~mL}$ peripheral blood of PBC patients $(n=5)$, PSC patients $(n=3)$ and HC $(n=3)$. They were stimulated with $10 \mathrm{mg} / \mathrm{mL}$ phytohemagglutinin for $72 \mathrm{~h}$. Then, BCECF-AM was added to PBMCs for $1 \mathrm{~h}$ and co-cultured with HiBECs. The adhesion rates of PBMCs were reflected by fluorescence intensity) (original magnification, $\times 200)$. (I) The adhesion rates of PBMCs were higher in PBC patients, compared to PSC and HC, ${ }^{*} p<0.05$, ${ }^{* *} p<0.01$. The $p$-value was determined by Student $t$-test. (D-H) PBMCs were extracted from $10 \mathrm{~mL}$ peripheral blood of $\mathrm{HC}(n=3)$, and they were stimulated with $10 \mathrm{mg} / \mathrm{mL}$ phytohemagglutinin for $72 \mathrm{~h}$. Then, BCECF-AM was added to PBMCs for $1 \mathrm{~h}$ and co-cultured with HiBECs that were treated by $17 \beta$-estradiol (10 nM) (E), PPT (100 nM) (F) and fulvestrant (8.24 $\mu$ M) (G,H) (original magnification, $\times 100)$. (J) The adhesion rates of PBMCs were higher in groups that were treated with $17 \beta$-estradiol and PPT, and it was blocked by fulvestrant $(8.24 \mu \mathrm{M}) .{ }^{*} p<0.05,{ }^{* \star} p<0.01$, determined by ANOVA with a Tukey test. All data are representative of three independent experiments.

\section{ER $\alpha$ Activation in HiBECs Facilitates PBMCs Recruitment}

In our previous assay of immunoblotting, we found the expression of PDC-E2 was up-regulated in HiBECs that were treated with 17ß-estradiol (Supplementary Figure 5). PDCE2 is the immunodominant autoantigen of PBC, and it is involved in breakdown of immunologic tolerance in a genetically susceptible individuals (28). Abnormal expression of PDC-E2 in normal HiBECs may activate immune system. Indeed, in this assay, we found that there were lots of activated immune cells in peripheral blood (PB) of $\mathrm{PBC}$ patients, and more prone to bind to HiBECs when compared with $\mathrm{HC}$ and patients with primary sclerosing cholangitis (PSC) (Figures 6A-C,I). Landi et al. (29) have proposed that the serum levels of multiple pro-inflammatory cytokines
(IL-6, IL-8, IL-2, IFN- $\gamma$, IL-23, and IL-1 $\beta$ ) in PBC patients were higher than that in PSC and HC, which may be related to immune cells activation. However, as mentioned above, the serum levels of pro-inflammatory cytokines were positively correlated with $\mathrm{ER} \alpha$ expression levels in small bile ducts of PBC patients. Hence, we wanted to observe the immunogenicity of HiBECs after $\mathrm{ER} \alpha$ activation.

PBMCs were isolated from $10 \mathrm{~mL}$ of blood samples of $4 \mathrm{HC}$. To obtain mitogen-activated immune cells, the PBMCs were stimulated with $10 \mathrm{mg} / \mathrm{mL}$ of phytohemagglutinin for $72 \mathrm{~h}$. Then, BCECF-AM was added to PBMCs for $1 \mathrm{~h}$. Meanwhile, $17 \beta$ estradiol $(10 \mathrm{nM})$ and PPT $(100 \mathrm{nM})$ were added to HiBECs parallel with vehicle and the fulvestrant was added to HiBECs $2 \mathrm{~h}$ before stimulation with $17 \beta$-estradiol. The PBMCs were added to HiBECs, which had been cultured for $48 \mathrm{~h}$. The 
results showed that the fluorescence intensity of $17 \beta$-estradiol $(10 \mathrm{nM})$ and PPT $(100 \mathrm{nM})$ groups were significantly higher than that of the controls $(0.1513 \pm 0.005,0.1628 \pm 0.017$ and $0.1196 \pm 0.016$, respectively) (Figures 6D-F,J). Indeed, we found that the ability of PBMCs binding to HiBECs was reduced by fulvestrant $(8.24 \mu \mathrm{M})$, when compared with $17 \beta$ estradiol (10 nM) groups (Fluorescence intensity: $0.1513 \pm 0.005$ vs. $0.0698 \pm 0.018$ ) (Figures $\mathbf{6 G}, \mathbf{H}, \mathbf{J}$ ). In addition, we repeated this assay using primary HiBECs and PBMCs that from same PBC patient and patients with Chronic Hepatitis B $(\mathrm{CHB})$. The results showed that PBMCs were prone to adhere to HiBECs that were isolated in $\mathrm{PBC}$ patient than in $\mathrm{CHB}$ patients (Supplementary Figure 6). Taken together, ER $\alpha$ activation in HiBECs would attract more PBMCs recruitment, which may be associated with pro- inflammatory cytokines.

\section{Up-Regulated Expression of CD54 in HiBECs After ER $\alpha$ Activation}

Previous studies indicate that the expression of CD54 (ICAM1), CD58 (LFA-3), and CD106 (VCAM-1) on HiBECs is altered by exposure of proinflammatory cytokines (IFN- $\gamma$ and TNF$\alpha$ ), and they are functional and necessary for the activity of cytotoxic effector lymphocytes (19). As described above, the proinflammatory cytokines might account for PBMCs recruitment. Hence, we determined whether PBMCs were more prone to bind to HiBECs was associated with up-regulated expression of adhesion molecules caused by ER $\alpha$-mediated pro-inflammatory cytokines. In the present study, flow cytometry was used to determine the expression levels of adhesion molecules (CD54, CD58, and CD106). Our results showed that HiBECs had highly expressed levels of CD54 $(99.6 \% \pm 0.21,99.4 \% \pm$ 0.38 and $99.5 \% \pm 0.26$ for controls, $17 \beta$-estradiol and PPT, respectively) (Figures 7A,B) and CD58 $(99.0 \% \pm 0.55,99.2 \%$ \pm 0.81 and $99.5 \% \pm 0.32$ for controls, $17 \beta$-estradiol and PPT, respectively)(Figures 7A,C), while they rarely expressed CD106 $(11.43 \% \pm 0.24,8.93 \% \pm 0.10$ and $8.76 \% \pm 0.12$ for controls, $17 \beta$ estradiol and PPT, respectively) (Figures 7A,D). However, $17 \beta$ estradiol and PPT can promoted CD54 expression, which was reflected in fluorescence intensity (Figure 7E). In addition, there were no any significant changes in CD58 and CD106 expression in HiBECs treated with $17 \beta$-estradiol and PPT (Figures 7F,G). As expected, fulvestrant had a negative role in regulating CD54 expression (Figure 7E).

To further confirm the results from in vitro assays, we selected some biopsies from 3 PBC patients, and tested whether CD54 expression can be detected in ER $\alpha$-positive bile ducts using immunofluorescence. Overall, this results were consistent with flow cytometry, and the location of CD54 was concentrated on ER $\alpha$-positive bile ducts (Figure $7 \mathbf{H}$ ). Hence, our results showed that immunogenicity of HiBECs was amplified by ER $\alpha$-mediated CD54 expression.

\section{JNK, STAT3 Activation and Cytokines Expressions Are Associated With ER $\alpha$-Positive Bile Ducts}

As indicated above, JNK and P38/STAT3 pathway were involved in $\mathrm{ER} \alpha$ - mediated cytokines expression. Hence, we wanted to confirm those results in vivo. The liver biopsies were obtained from 8 PBC patients, and those proteins were detected using immunohistochemistry. We found positive staining of $\mathrm{P}$ JNK and P-STAT3 in interlobular bile ducts of PBC patients (Figure 8A), but they were rarely expressed in HC (Figure 8A). At same time, we also found positive expression of IL-6, IL8 and TNF- $\alpha$ in small bile ducts of PBC patients (Figure 8D). Immunohistochemical analysis showed that those proteins expression levels in small bile ducts of $\mathrm{PBC}$ patients were higher than that in $\mathrm{HC}$ (Figures $\mathbf{8 B}, \mathbf{C}, \mathbf{E}-\mathbf{G}$ ).

\section{DISCUSSION}

Intrahepatic bile duct system is one of the target tissues of estrogen. Estrogen plays a vital role in tissue repairing after liver injury, regeneration after liver partial resection, improving insulin resistance and preventing liver fat deposition (30). However, female may develop liver diseases (hepatomegaly, intrahepatic cholestasis and even liver failure), who are receiving long-term estrogen to establish an artificial menstrual cycle (31), pregnant (32), or suffer from $\mathrm{CHB}$ (33). The reasons were related with the estrogen levels rise dramatically (33). Hence, estrogen may play a dual role in the physiology and pathology of liver. For a long time, estrogen is using to induce intrahepatic cholestasis of rodents (34). So, estrogen administration is avoided in $\mathrm{PBC}$ patients. However, Olsson et al. have proposed that estrogen replacement therapy (as anti-osteoporosis drugs) is safe in PBC patients; they have found that PBC patients with osteoporosis receiving long-time estrogen replacement therapy show no effect on disease development. Even high concentration of estrogen is considered as a protective factor against disease progression in PBC (35). Indeed, some clinical observations of small sample of patients have found that serum enzymes of untreated $\mathrm{PBC}$ patients receiving estrogen administration are down-regulated (35-37). Hence, those clinical studies seem to rediscover the concept that estrogen administration in $\mathrm{PBC}$ patients exerts deleterious effects on the liver. Nevertheless, as Invernizzi reported previously, the levels of AKP and $\gamma$ GT were are decreased more than $60 \%$ of baseline in $\mathrm{PBC}$ patients, who have received tamoxifen (estrogen antagonist), but a complete reversal in case after tamoxifen withdrawal (38). As mentioned above, estrogens exert physiology function mainly via ER receptors. Hence, it is very interesting to clarify the functions of ER receptors in $\mathrm{PBC}$.

$\mathrm{ER} \alpha$, a classical estrogen receptor, is involved in multiple physiological functions of estrogen, such as proliferation of hormone-associated cancer cells and biliary epithelial cells (BECs) (39), and tissue regeneration after partial resection of liver $(15,16)$. Additionally, it is also shown that estrogen promotes immune cells to product type I IFN via activated $\mathrm{ER} \alpha(40)$ and triggers pro-inflammatory cytokines expression in BECs (19). Previously, Alvaro et al. (13) have proposed the $\mathrm{ER} \alpha$ expression levels in small bile ducts of PBC patients are correlated with the progression of disease; they consider that the abnormal expression of $\mathrm{ER} \alpha$ in ducts is a reason that this disease progresses to ductopenia, although they have not explain the underling mechanism. Recently, Meyer et al. (17) have found that the environment around landfill sites contain higher levels of 


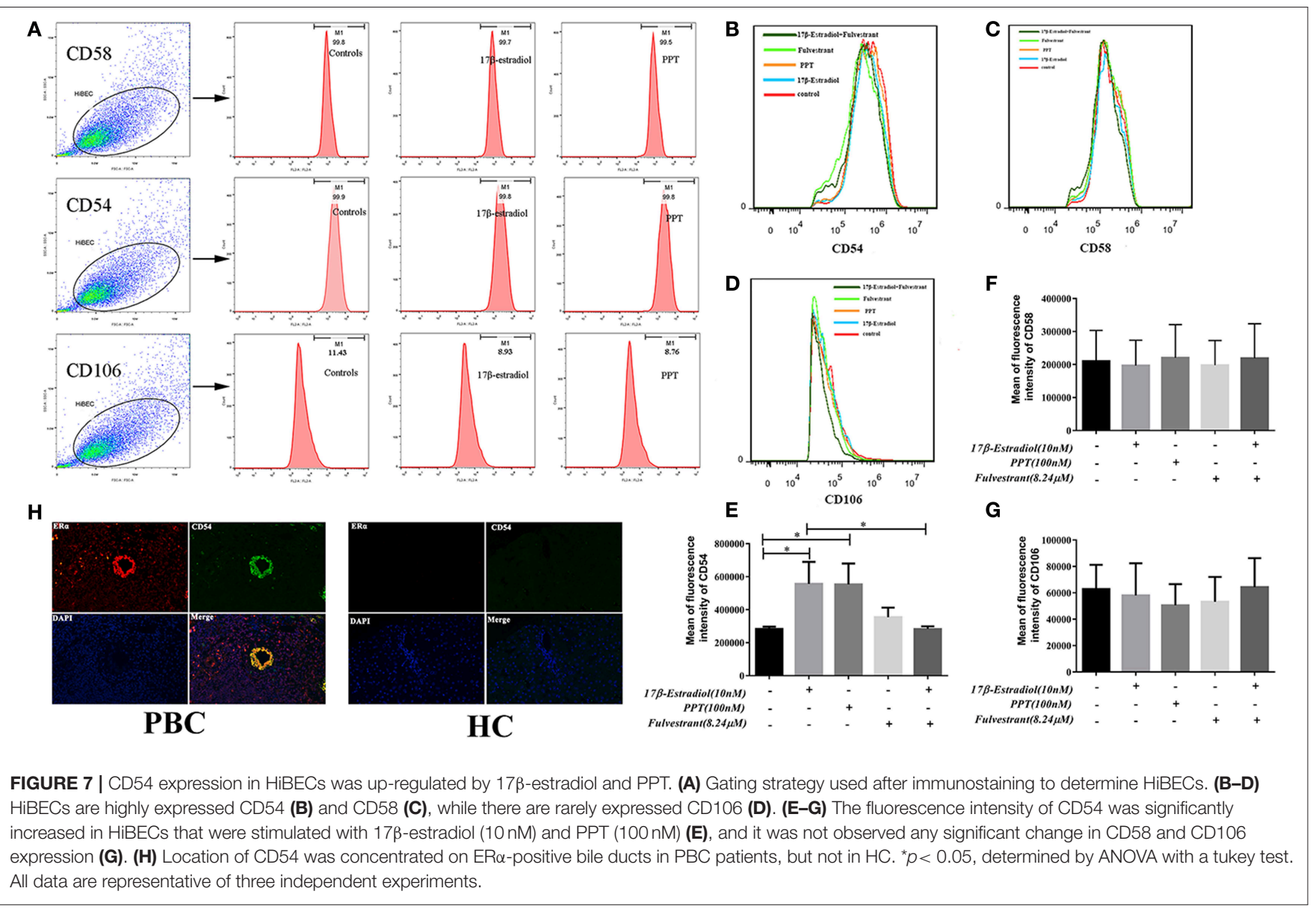

xenobiotic which activated the human ER $\alpha$ in a dose-dependent manner may trigger PBC. And, this is supported by a follow-up study showing that the soil in the high incidence area of PBC contains a large amount of xenobiotic that can activate ER $\alpha$ (15). Coincidentally, we were considering the reason of the onset of $\mathrm{PBC}$ might be associated with the living environment, which stemmed from a survey that screening of anti- mitochondrial antibody subtype M2 (AMA-M2) in 19012 residents of shanghai; pollution and household smoking and living near the landfill sites are considered the risk factors by our analysis (41). In addition, sunset yellow and tartrazine, as Axon A et al. found (42), may induce the onset of PBC. They are very common chemicals in our living environment (coal-derived food and cosmetic colorings) and regarded as novel human ER $\alpha$ activators, which can provoke $\mathrm{ER} \alpha$ activation in very small amounts. Hence, the above studies indicate that $\mathrm{ER} \alpha$ activation induced by xenoestrogen and estrogen-like compounds of environment plays a pivotal role in the onset of PBC.

However, why post-menopausal women are susceptible to $\mathrm{PBC}$, who have low endogenous estradiol levels is not clear. There are some possible explanations. The first is that the chronic exposure to xenoestrogens or estrogen-like compounds may activate $\mathrm{ER} \alpha$ in cholangiocytes, and cholangiocytes will transform into "immunogenicity of individual" (expression pro-inflammatory cytokines and adhesion molecules) after ER $\alpha$ pathway activation. The second is that estrogens stimulate BEC cytokine production is related to ER $\alpha$-expression, which is higher in female than male BECs (21). The other is that low estrogen levels of post-menopausal women have lost the ability to suppress the immune system, because ER $\alpha$ mRNAs or proteins are expressed in mature immune cells (B cells, CD4 ${ }^{+} \mathrm{T}$ cells, $\mathrm{CD}^{+} \mathrm{T}$ cells, Monocytes, and DCs), and higher doses of ectopic estrogens typically suppress immune cell activation (43).

In the present study, we proposed that the expression of pro-inflammatory cytokines will be increased in HiBECs after ER $\alpha$-mediated pathway activation. Multiple studies have confirmed that pro-inflammatory cytokines play an important immune mediating role in the pathogenesis of PBC. IL- 6 is a multifunctional cytokine, which is best known for its role in the liver acute phase response. IL- 6 can promote hepatocellular carcinoma (HCC) growth and metastasis via antagonism of TNF$\alpha$ and IL- $1 \beta$ immune response $(44,45)$. It contributes to the development of autoimmunity disease via activating Th17 cells and inhibiting the Treg cells function. Kumiko et al. (21) have considered that BECs have different IL- 6 production, which is the reason that females are more susceptible than males to several biliary tract diseases (PBC, autoimmune hepatitis and polycystic livers). In the course of PBC disease, IL-6 establishes a 


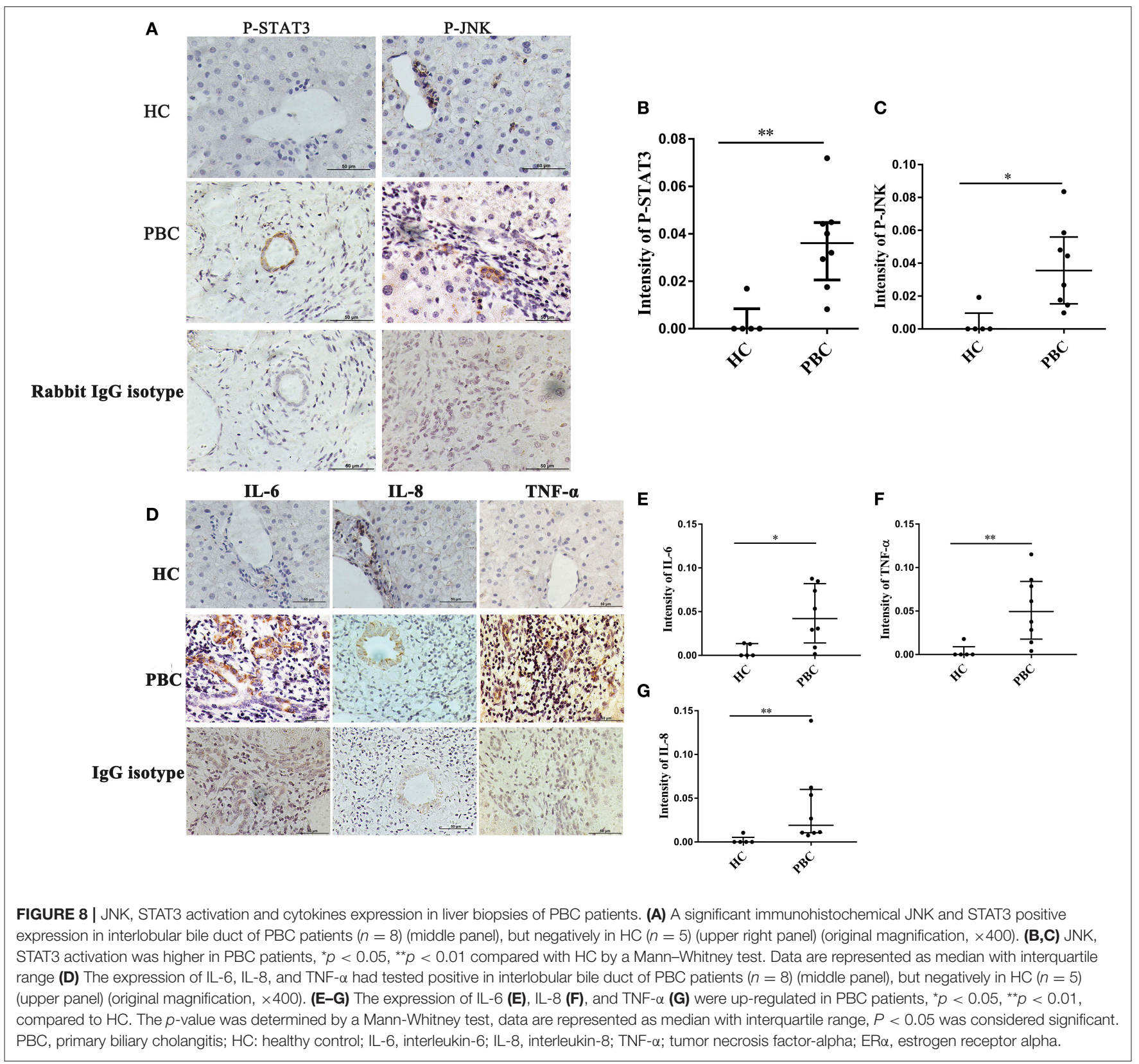

vicious circle of HiBECs damage. HiBECs will express CD44 after AMA binds to them, and it will induce monocytes recruitment and release IL-6. As a feedback loop, the level of AMA is upregulated by B cells in the presence of IL-6 (46). Similar to IL-6, serum high levels of IL- 8 also contributes to PBC development (47). During the course of chronic liver diseases (CLD), IL-8 mainly activates leukocytes, $\mathrm{T}$ lymphocytes and macrophages, and recruits them to the acute inflammatory site $(48,49)$. The pathogenesis of IL-8 in PBC is related to neutrophil infiltration, and the neutrophilic inflammation in interlobular bile duct will induce a large number of other inflammatory cells migration, and provoke the damage and apoptosis of HiBECs (50). The immune cascade in small bile ducts will be aggravated by lots of immune cells recruitment. Therefore, some researchers have noted that baseline serum levels of pro-inflammatory cytokine (TNF- $\alpha$ ) were significantly higher in PBC patients with advanced disease (stage III/IV) than in PBC patients with early disease (51).

However, we found the expression of target antigen (PDC-E2) was also up-regulated in HiBECs, as well as pro-inflammatory cytokines, when ER $\alpha$ was activated by estrogen or PPT. Therefore, we considered that the HiBECs would transform into an "inflammatory cellular phenotype" after ER $\alpha$ was abnormal activated. Hence, there would be a strong attraction for immune cells. As expected, subsequent adhesion experiments found that PBMCs are prone to bind to HiBECs, which were treat with $17 \beta$-estradiol and PPT, and it also was proved by primary HiBECs and PBMCs from same PBC patient. 
In addition, the up-regulated expression of CD54 was to be found in $E R \alpha$-positive bile ducts and HiBECs that high expression of ER $\alpha$. CD54 is a ligand for lymphocyte functionassociated antigen-1, also known as intracellular adhesion molecule-1 (ICAM-1), is involved in T cell-induced autoimmune disease (52).

Of note, there were some limitations in the present study. First, the patient sample was limited in sample size. It was extremely lack for PBC patients, especially those who needed liver pathology to confirm this disease. Therefore, the positive correlation between $\mathrm{ER} \alpha$ expression levels and the levels of cytokines need to be further confirmed by a large sample size. Second, although it was observed that ER $\alpha$ was expressed in the bile duct system, further studies need to detect the $\mathrm{ER} \alpha$ expression levels and cytokines at the different $\mathrm{PBC}$ stages, providing a more detailed complement on the pathogenicity of $\mathrm{ER} \alpha$ in PBC development. Finally, although the number of patients with AMA seemed very large, few people would develop recognizable PBC (53), and it needed to be investigated whether $\mathrm{ER} \alpha$ was expressed in small bile ducts of AMA positive patients would be more susceptible to progress to recognizable $\mathrm{PBC}$. In addition, nonresponse $\mathrm{PBC}$ patients who received long-term UDCA therapy would allow us to evaluate the effect of ER $\alpha$ antagonism, which had been exerted a rational therapeutic strategy in sexbased mortality gap in cystic fibrosis and other inflammatory lung illnesses (54). Nevertheless, our results suggested an important role of abnormal $\mathrm{ER} \alpha$ expression in cholangiocytes in inducing intrahepatic bile duct inflammation of $\mathrm{PBC}$, providing a therapeutic strategy or a preventive approach for PBC.

\section{REFERENCES}

1. European Association for the Study of the Liver. EASL Clinical Practice Guidelines: the diagnosis and management of patients with primary biliary cholangitis. J Hepatol. (2017) 67:145-72. doi: 10.1016/j.jhep.2017. 03.022

2. Lleo A, Jepsen P, Morenghi E, Carbone M, Moroni L, Battezzati PM, et al. Evolving trends in female to male incidence and male mortality of primary biliary cholangitis. Sci Rep. (2016) 6:25906. doi: 10.1038/srep 25906

3. Jepsen P, Gronbaek L, Vilstrup H. Worldwide incidence of autoimmune liver disease. Dig Dis. (2015) 33 (Suppl. 2):2-12. doi: 10.1159/0004 40705

4. Boonstra K, Kunst AE, Stadhouders PH, Tuynman HA, Poen AC, van Nieuwkerk KM, et al. Rising incidence and prevalence of primary biliary cirrhosis: a large population-based study. Liver Int. (2014) 34:e318. doi: $10.1111 /$ liv.12434

5. Webb GJ, Hirschfield GM. Primary biliary cholangitis in 2016: Highdefinition PBC: biology, models and therapeutic advances. Nat Rev Gastroenterol Hepatol. (2017) 14:76-8. doi: 10.1038/nrgastro.2016.201

6. Tsuneyama K, Baba H, Morimoto Y, Tsunematsu T, Ogawa H. Primary biliary cholangitis: its pathological characteristics and immunopathological mechanisms. J Med Invest. (2017) 64:7-13. doi: 10.2152/jmi.64.7

7. Sasaki M, Kakuda Y, Miyakoshi M, Sato Y, Nakanuma Y. Infiltration of inflammatory cells expressing mitochondrial proteins around bile ducts and in biliary epithelial layer may be involved in the pathogenesis in primary biliary cirrhosis. J Clin Pathol. (2014) 67:470-6. doi: 10.1136/jclinpath-2013-201917

\section{DATA AVAILABILITY STATEMENT}

The raw data supporting the conclusions of this article will be made available by the authors, without undue reservation, to any qualified researcher.

\section{ETHICS STATEMENT}

The study was approved by the Institutional Review Board of Longhua Hospital (No. 2014LCSY09). All subjects gave written informed consent in accordance with the Declaration of Helsinki.

\section{AUTHOR CONTRIBUTIONS}

WZ designed and supervised the project and obtained funding. $\mathrm{HC}, \mathrm{YQ}$, and BZ performed clinical diagnosis and treatment, collected samples, and contributed to data collection. HC performed bioinformatics and statistical analysis and drafted the manuscript.

\section{FUNDING}

This study was funded by the National Natural Science Foundation of China (Grant no. 81673926).

\section{SUPPLEMENTARY MATERIAL}

The Supplementary Material for this article can be found online at: https://www.frontiersin.org/articles/10.3389/fimmu. 2019.02815/full\#supplementary-material

8. Lleo A, Shimoda S, Ishibashi H, Gershwin ME. Primary biliary cirrhosis and autoimmune hepatitis: apotopes and epitopes. J Gastroenterol. (2011) 46 (Suppl. 1):29-38. doi: 10.1007/s00535-010-0303-8

9. Tsuneyama K, Van de Water J, Leung PS, Cha S, Nakanuma Y, Kaplan M, et al. Abnormal expression of the E2 component of the pyruvate dehydrogenase complex on the luminal surface of biliary epithelium occurs before major histocompatibility complex class II and BB1/B7 expression. Hepatology. (1995) 21:1031-7. doi: 10.1002/hep.1840210422

10. Rong GH, Yang GX, Ando Y, Zhang W, He XS, Leung PS, et al. Human intrahepatic biliary epithelial cells engulf blebs from their apoptotic peers. Clin Exp Immunol. (2013) 172:95-103. doi: 10.1111/cei.12046

11. Rong G, Zhong R, Lleo A, Leung PS, Bowlus CL, Yang GX, et al. Epithelial cell specificity and apotope recognition by serum autoantibodies in primary biliary cirrhosis. Hepatology. (2011) 54:196-203. doi: 10.1002/hep. 24355

12. Shimoda S, Harada K, Niiro H, Yoshizumi T, Soejima Y, Taketomi A, et al. Biliary epithelial cells and primary biliary cirrhosis: the role of liver-infiltrating mononuclear cells. Hepatology. (2008) 47:958-65. doi: 10.1002/hep.22102

13. Alvaro D, Invernizzi P, Onori P, Franchitto A, De Santis A, Crosignani A, et al. Estrogen receptors in cholangiocytes and the progression of primary biliary cirrhosis. J Hepatol. (2004) 41:905-12. doi: 10.1016/j.jhep.2004.08.022

14. Ascenzi P, Bocedi A, Marino M. Structure-function relationship of estrogen receptor alpha and beta: impact on human health. Mol Aspects Med. (2006) 27:299-402. doi: 10.1016/j.mam.2006.07.001

15. Alvaro D, Alpini G, Onori P, Perego L, Svegliata Baroni G, Franchitto A, et al. Estrogens stimulate proliferation of intrahepatic biliary epithelium in rats. Gastroenterology. (2000) 119:1681-91. doi: 10.1053/gast.2000.20184 
16. Batmunkh B, Choijookhuu N, Srisowanna N, Byambatsogt U, Synn Oo P, Noor Ali M, et al. Estrogen accelerates cell proliferation through estrogen receptor alpha during rat liver regeneration after partial hepatectomy. Acta Histochem Cytochem. (2017) 50:39-48. doi: 10.1267/ahc. 17003

17. Meyer SK, Probert PM, Lakey AK, Leitch AC, Blake LI, Jowsey PA, et al. Environmental xenoestrogens super-activate a variant murine ER beta in cholangiocytes. Toxicol Sci. (2017) 156:54-71. doi: 10.1093/toxsci/kfw234

18. Probert PM, Leitch AC, Dunn MP, Meyer SK, Palmer JM, Abdelghany TM, et al. Identification of a xenobiotic as a potential environmental trigger in primary biliary cholangitis. J Hepatol. (2018) 69:1123-35. doi: 10.1016/j.jhep.2018.06.027

19. Leon MP, Bassendine MF, Gibbs P, Thick M, Kirby JA. Immunogenicity of biliary epithelium: study of the adhesive interaction with lymphocytes. Gastroenterology. (1997) 112:968-77. doi: 10.1053/gast.1997.v112.pm90 41260

20. Korlipara LV, Leon MP, Rix DA, Douglas MS, Gibbs P, Bassendine MF, et al. Development of a flow cytometric assay to quantify lymphocyte adhesion to cytokine-stimulated human endothelial and biliary epithelial cells. J Immunol Methods. (1996) 191:121-30. doi: 10.1016/0022-1759(96)00002-6

21. Isse K, Specht SM, Lunz JG, Kang LI, Mizuguchi Y, Demetris AJ. Estrogen stimulates female biliary epithelial cell interleukin-6 expression in mice and humans. Hepatology. (2010) 51:869-80. doi: 10.1002/hep. 23386

22. Li T, Huang Y, Liu P, Liu Y, Guo J, Zhang W, et al. Lower plasma levels of IL-35 in patients with primary biliary cirrhosis. Tohoku J Exp Med. (2018) 244:123-31. doi: 10.1620/tjem.244.123

23. Alvaro D, Onori P, Metalli VD, Svegliati-Baroni G, Folli F, Franchitto A, et al. Intracellular pathways mediating estrogeninduced cholangiocyte proliferation in the rat. Hepatology. (2002) 36:297-304. doi: 10.1053/jhep.2002.34741

24. Boaglio AC, Zucchetti AE, Toledo FD, Barosso IR, Sánchez Pozzi EJ, Crocenzi FA, et al. ERK1/2 and p38 MAPKs are complementarily involved in estradiol 17ss-D-glucuronide-induced cholestasis: crosstalk with cPKC and PI3K. PLoS ONE. (2012) 7:e49255. doi: 10.1371/journal.pone.00 49255

25. Tormos AM, Arduini A, Talens-Visconti R, del Barco Barrantes I, Nebreda AR, Sastre J. Liver-specific p38 $\alpha$ deficiency causes reduced cell growth and cytokinesis failure during chronic biliary cirrhosis in mice. Hepatology. (2013) 57:1950-61. doi: 10.1002/hep.26174

26. Darnell JE. STATs and gene regulation. Science. (1997) 277:16305. doi: 10.1126/science.277.5332.1630

27. Lu H, Wu Y, Shao X, Zhou S, Jiang Y, Chen R, et al. ANG II facilitated CD11(+) Ly6C(hi) cells reprogramming into M1-like macrophage through Erk1/2 or p38-Stat3 pathway and involved in EAM. J Leukoc Biol. (2018) 103:719-30. doi: 10.1002/JLB.3A0617-264RR

28. Mao TK, Davis PA, Odin JA, Coppel RL, Gershwin ME. Sidechain biology and the immunogenicity of PDC-E2, the major autoantigen of primary biliary cirrhosis. Hepatology. (2004) 40:1241-8. doi: 10.1002/hep.20491

29. Landi A, Weismuller TJ, Lankisch TO, Santer DM, Tyrrell DL, Manns MP, et al. Differential serum levels of eosinophilic eotaxins in primary sclerosing cholangitis, primary biliary cirrhosis, and autoimmune hepatitis. J Interferon Cytokine Res. (2014) 34:204-14. doi: 10.1089/jir.2013.0075

30. Zhu L, Brown WC, Cai Q, Krust A, Chambon P, McGuinness OP, et al. Estrogen treatment after ovariectomy protects against fatty liver and may improve pathway-selective insulin resistance. Diabetes. (2013) 62:42434. doi: $10.2337 / \mathrm{db} 11-1718$

31. van Erpecum KJ, Janssens AR, Kreuning J, Ruiter DJ, Kroon HM, Grond AJ. Generalized peliosis hepatis and cirrhosis after long-term use of oral contraceptives. Am J Gastroenterol. (1988) 83:572-5.

32. Not in NCBIWestbrook RH, Dusheiko G, Williamson C. Pregnancy and liver disease. J Hepatol. (2016) 64:933-45. doi: 10.1016/j.jhep.2015. 11.030

33. Macek Jilkova Z, Decaens T, Marlu A, Marche H, Jouvin-Marche E, Marche PN. Sex differences in spontaneous degranulation activity of intrahepatic natural killer cells during chronic hepatitis B: association with estradiol levels. Mediators Inflamm. (2017) 2017:3214917. doi: 10.1155/2017/3214917
34. Song X, Vasilenko A, Chen Y, Valanejad L, Verma R, Yan B, et al. Transcriptional dynamics of bile salt export pump during pregnancy: mechanisms and implications in intrahepatic cholestasis of pregnancy. Hepatology. (2014) 60:1993-2007. doi: 10.1002/hep. 27171

35. Olsson R, Mattsson LA, Obrant K, Mellström D. Estrogenprogestogen therapy for low bone mineral density in primary biliary cirrhosis. Liver. (1999) 19:188-92. doi: 10.1111/j.1478-3231.1999.tb 00034.x

36. Guattery JM, Faloon WW. Effect of estradiol upon serum enzymes in primary biliary cirrhosis. Hepatology. (1987) 7:737-42. doi: 10.1002/hep.18400 70420

37. Ormarsdóttir S, Mallmin H, Naessén T, Petrén-Mallmin M, Broomé U, Hultcrantz R, et al. An open, randomized, controlled study of transdermal hormone replacement therapy on the rate of bone loss in primary biliary cirrhosis. J Intern Med. (2004) 256:63-9. doi: 10.1111/j.1365-2796.2004. 01342.x

38. Invernizzi P, Alvaro D, Crosignani A, Gaudio E, Podda M. Tamoxifen in treatment of primary biliary cirrhosis. Hepatology. (2004) 39:11756. doi: 10.1002/hep.20164

39. Acconcia F, Fiocchetti M, Marino M. Xenoestrogen regulation of ER $\alpha / E R \beta$ balance in hormone-associated cancers. Mol Cell Endocrinol. (2017) 457:312. doi: 10.1016/j.mce.2016.10.033

40. Kovats S.Kovats S. Estrogen receptors regulate innate immune cells and signaling pathways. Cell Immunol. (2015) 294:639. doi: 10.1016/j.cellimm.2015.01.018

41. Chen BH, Wang QQ, Zhang W, Zhao LY, Wang GQ. Screening of antimitochondrial antibody subtype M2 in residents at least 18 years of age in an urban district of Shanghai, China. Eur Rev Med Pharmacol Sci. (2016) 20:2052-60.

42. Axon A, May FE, Gaughan LE, Williams FM, Blain PG, Wright MC. Tartrazine and sunset yellow are xenoestrogens in a new screening assay to identify modulators of human oestrogen receptor transcriptional activity. Toxicology. (2012) 298:40-51. doi: 10.1016/j.tox.2012. 04.014

43. Lambert KC, Curran EM, Judy BM, Milligan GN, Lubahn DB, Estes DM. Estrogen receptor alpha $(\mathrm{ER} \alpha)$ deficiency in macrophages results in increased stimulation of $\mathrm{CD} 4+\mathrm{T}$ cells while $17 \beta$-estradiol acts through ER $\alpha$ to increase IL-4 and GATA-3 expression in CD4+ T cells independent of antigen presentation. J Immunol. (2005) 175:571623. doi: 10.4049/jimmunol.175.9.5716

44. He G, Karin M. NF- $\mathrm{\kappa B}$ and STAT3 - key players in liver inflammation and cancer. Cell Res. (2011) 21:159-68. doi: 10.1038/cr.2010.183

45. Sternak M, Jakubowski A, Czarnowska E, Slominska EM, Smolenski RT, Szafarz M, et al. Differential involvement of IL-6 in the early and late phase of 1-methylnicotinamide (MNA) release in Concanavalin A-induced hepatitis. Int Immunopharmacol. (2015) 28:105-14. doi: 10.1016/j.intimp.2015. 04.053

46. Xu B, Broome U, Ericzon BG, Sumitran-Holgersson S. High frequency of autoantibodies in patients with primary sclerosing cholangitis that bind biliary epithelial cells and induce expression of CD44 and production of interleukin 6. Gut. (2002) 51:120-7. doi: 10.1136/gut.51.1.120

47. Umemura T, Sekiguchi T, Joshita S, Yamazaki T, Fujimori N, Shibata $\mathrm{S}$, et al. Association between serum soluble CD14 and IL-8 levels and clinical outcome in primary biliary cholangitis. Liver Int. (2017) 37:897905. doi: 10.1111/liv.13316

48. Zimmermann HW, Seidler S, Gassler N, Nattermann J, Luedde T, Trautwein $\mathrm{C}$, et al. Interleukin-8 is activated in patients with chronic liver diseases and associated with hepatic macrophage accumulation in human liver fibrosis. PLoS ONE. (2011) 6:e21381. doi: 10.1371/journal.pone.00 21381

49. Baggiolini M, Walz A, Kunkel SL. Neutrophil-activating peptide-1/interleukin 8, a novel cytokine that activates neutrophils. J Clin Invest. (1989) 84:10459. doi: 10.1172/JCI114265

50. Isse K, Harada K, Nakanuma Y. IL-8 expression by biliary epithelial cells is associated with neutrophilic infiltration and reactive bile ductules. Liver Int. (2007) 27:672-80. doi: 10.1111/j.1478-3231.2007.01465.x 
51. Neuman M, Angulo P, Malkiewicz I, Jorgensen R, Shear N, Dickson ER, et al. Tumor necrosis factor-alpha and transforming growth factor-beta reflect severity of liver damage in primary biliary cirrhosis. J Gastroenterol Hepatol. (2002) 17:196-202. doi: 10.1046/j.1440-1746.2002.02672.x

52. Svedova J, Ménoret A, Mittal P, Ryan JM, Buturla JA, Vella AT. Therapeutic blockade of CD54 attenuates pulmonary barrier damage in T cell-induced acute lung injury. Am J Physiol Lung Cell Mol Physiol. (2017) 313:L17791. doi: 10.1152/ajplung.00050.2017

53. Abe M, Onji M. Natural history of primary biliary cirrhosis. Hepatol Res. (2008) 38:639-45. doi: 10.1111/j.1872-034X.2008. 00351.x

54. Abid S, Xie S, Bose M, Shaul PW, Terada LS, Brody SL, et al. 17 $\beta$-Estradiol dysregulates innate immune responses to Pseudomonas aeruginosa respiratory infection and is modulated by estrogen receptor antagonism. Infect Immun. (2017) 85:e00422-17. doi: 10.1128/IAI.00422-17

Conflict of Interest: The authors declare that the research was conducted in the absence of any commercial or financial relationships that could be construed as a potential conflict of interest.

Copyright (C) 2019 Cao, Zhu, Qu and Zhang. This is an open-access article distributed under the terms of the Creative Commons Attribution License (CC BY). The use, distribution or reproduction in other forums is permitted, provided the original author(s) and the copyright owner(s) are credited and that the original publication in this journal is cited, in accordance with accepted academic practice. No use, distribution or reproduction is permitted which does not comply with these terms. 